\author{
2021, Volume 8, ID 491 \\ Research Articles \\ DOI: $10.15342 / \mathrm{ijms.2021.491}$
}

\title{
The Correlation between Functional Parameters (6-Minute Walk Test) and Life Quality of Silicosis Patients: Case Study in the Jerada City in Morocco
}

\author{
Meryem Karhate Andaloussi a (iD, Lamiyae.Senhaji a, Michele Germain ${ }^{\mathrm{b}}$, Jean-Marie Casillas c, \\ Abderrazak Hajjioui ${ }^{\mathrm{d}}$ \\ ${ }^{a}$ Center of Pneumology and Silicosis, Jerada, Morocco. \\ ${ }^{\mathrm{b}}$ Respiratory Functional Exploration Service, Croix Rousse Hospital Rơr, Lyon, France. \\ ${ }^{c}$ Physical and Rehabilitation Physician, University Hospital Center Dijon Rór, Dijon, France. \\ d Department of Physical Medicine and Rehabilitation, Hassan II University Hospital Center Fes Rór, \\ Morocco.
}

\begin{abstract}
Introduction: Silicosis is pneumoconiosis secondary to the inhalation of mineral dust containing silica. It represents a real public health problem in the city of Jerada.

Purposes: To assess the functional parameters of silicosis patients (based on the 6-minute walk test (6MWT)) and their impact on our patients' quality of life (Saint George's respiratory questionnaire (SGRQ) and hospital anxiety and depression scale (HAD))

Materials and methodology: A cross-sectional study of 147 patients with silicosis. It is designed to collect their socio-demographic data. And assess their respiratory function (6MWT) and quality of life (SGRQ).

Findings: The average age of our patients was $64.08+/-6.46$ years [46 -81]. At 6MWT, the mean distance walked by our patients is $326.8+/-168.47 \mathrm{~m}(30-835)$ or $59 \%$ of the predicted distance, with a median of $360 \mathrm{~m}$. The mean total Saint George score (SGT) was $68.02+/-$ 19.54\%. The means of the other Saint George scores were: symptoms (SGS): $45.95+/-$ 23.66\%, activities (SGA): $79.58+/-19.8 \%$, and impact (SGI): 68, Results: The average age of our patients was $64.08+/-6.46$ years [46 -81]. At 6MWT, the mean distance walked by our patients is $326.8+/-168.47 \mathrm{~m}(30-835)$ or $59 \%$ of the predicted distance, with a median of $360 \mathrm{~m}$. The mean total Saint George score (SGT) was $68.02+/-19.54 \%$. The means of the other Saint George scores were: symptoms (SGS): $45.95+/-23.66 \%$, activities (SGA): 79.58 +/- $19.8 \%$, and impact (SGI): $68.32+/-22.33 \%$. We found a statistically significant relationship between dyspnea, quality of life, anxiety, and walking distance.

Conclusion: The study demonstrated that silicosis is a pulmonary disease that causes significant functional limitation and deterioration of life quality.
\end{abstract}

Keywords: Silicosis, 6 min Walking Test, Saint George Respiratory Questionnaire, Quality of Life, Morocco

Received: 18 Apr 2021; Revised: 10 Aug 2021; Accepted: 12 Aug 2021; Published: 04 Oct 2021

Correspondence: Meryem Karhate Andaloussi, The Correlation between Functional Parameters (6-Minute Walk Test) and Life Quality of Silicosis Patients: Case Study in the Jerada City in Morocco. Email: meryem.karhate@gmail.com

Cite this article as: Karhate Andaloussi M, Senhaji L, Germain M, Casillas J-M, Hajjioui A. The Correlation between Functional Parameters (6-Minute Walk Test) and Life Quality of Silicosis Patients: Case Study in the Jerada City in Morocco. Integr J Med Sci. 2021;8:491. [https://doi.org/10.15342/ijms.2021.491]. 
Copyright (C) 2021 Meryem Karhate Andaloussi et al. This is an open access article distributed under the Creative Commons Attribution 4.0 International License, which permits unrestricted use, distribution, and reproduction in any medium, provided the original work is properly cited.

\section{INTRODUCTION}

Silicosis is a worldwide occupational lung disease. It is caused by exposure to crystalline silica dust, which occurs in various industries. Silicosis occurs due to an imbalance between the penetration of particles and the means of bronchopulmonary purification and the toxicity of silica, and the repair methods. Exposure to crystalline silica dust occurs in many industries. The occurrence of silicosis results from an imbalance between the penetration of particles and the means of bronchopulmonary purification, as well as the toxicity of silica and the means of repair [1-3].

The pathophysiology of this pneumoconiosis involves two phases: a phase of alveolitis after capturing the mineral particles by the alveolar macrophage and a later phase of fibrosis. Histologically, the elementary lesion is the silicosis nodule. The silicosis nodules will later increase in size, coalesce and then give pseudo-tumoral masses characteristic of coal miner's pneumoconiosis [2].

In the 1990s, more than three million people were exposed to silica in Europe. Also, in Spain, annual reports from the National Institute of Silicosis show that since 2008 there has been an increase in the number of new cases. In 2012, 166 patients were reported.[3] .In the United States, the annual incidence is reported to be between 36,500 and 37,300 cases, with nearly 2,700 deaths over a decade.[1] In the UK, approximately 600,000 workers were exposed to crystalline silica from 1990 to 1993, about 100 cases were reported each year between 1996 and 2009, and deaths from silicosis decreased from 28 in 1993 to 10 in 2008[4-5].

China has the most significant number of silicosis patients, with over 500,000 cases recorded between 1991 and 1995, 6,000 new cases, and over 24,000 deaths reported each year [1,3]. Morocco also counts many patients affected by silicosis, especially in Jerada city, where this disease is considered a priority and presents a significant public health issue. Jerada is a city located in the eastern region of Morocco, and it was founded in 1927 after the discovery of the coal basin. The mining activity was started in 1936, and the mine was closed in 1998.[67].

After 60 years of mining, there was no additional activity in Jerada. The city counted 9000 workers after the closure of the mine in 1998, including 2018 silicosis (currently 1470 silicosis still alive in 2018. [6-7]

Due to the lack of other financial resources, new clandestine coal mines have arisen, causing new, more complicated, and earlier cases of pulmonary silicosis.

Silicosis is an incurable disease with infectious, cardiovascular, osteoarticular, nutritional, metabolic, and psychological (anxiety, depression) complications [2, 8].

The 6-min walk test (6MWT) is a simple and inexpensive tool for assessing exercise tolerance.

It applies to many diseases, including chronic obstructive pulmonary disease and idiopathic pulmonary fibrosis (IPF), and is used to assess functional status and therapeutic response and define prognosis [9].

For better patient management, the clinician should not be satisfied with assessing the patient's health. They must be interested in the patient's perception of his health status, which explains the use of quality-of-life measures that better understand the areas in which patients feel their disease's consequences. The Saint George questionnaire is designed specifically for patients with respiratory pathology. All of its items relate more or less directly to the symptoms of these pathologies (breathlessness, wheezing) or their consequences on daily life. [10].

In the context of a respiratory rehabilitation program destined for silicosis patients of Jerada city, this study was conducted to evaluate the functional status of our patients by the 6MWT and its impact on their life quality (SGRQ and HAD).

\section{METHODS}

Study nature

We conducted a cross-sectional study between December 2017 and June 2018 at the Pneumology and Silicosis Center of Jerada. Including patients with silicosis monitored in consultation. We conducted our survey by two experienced physicians consisting of a faceto-face interview. We informed the patients about the study's nature, obtained their consent, and collected their data.

The ethical committee approved our protocol of Sidi Mohammed Ben Abdellah University. 
Seven hundred (700) patients live in the city of Jerada, 330 of whom are regularly followed up in consultation. One hundred forty-seven patients were included in our study, i.e., a participation rate of $44.5 \% .183$ patients were excluded (Participation refusal, geographical distance, reduced walking mobility/loss of autonomy, acute cardiac or respiratory decompensation at survey time.)

Data collection:

Data collected in these studies included: clinical data (dyspnea, comorbidities), demographic data (age), smoking status, exposure history (mean exposure time, latency time, permanent partial incapacity: PPI), lung function (6MWT), quality of life (Moroccan version of the Saint George questionnaire [11], HAD test [12].

Quality of life (QoL)

QoL was evaluated through the St George respiratory questionnaire with its 3 main items (symptoms, activities, and impact), as well as the HAD test to diagnose anxious and depressed patients.

6-minute walk test.

The 6MWT is a simple tool that has shown its validity to assess exercise tolerance. Our patients walked a 30-meter round-trip corridor, and they were instructed to walk at their own pace and stop if necessary but were encouraged to complete the test. The walking test was classified into 3 stages from 0 to 3 : the greater the stage, the greater the limitation.

Statistical analysis

Patient data collected on the operating form were entered into an Excel spreadsheet.

The data were statistically analyzed using SPSS software version 22.0.

\section{RESULTS}

We collected 147 patients, all of them were male. The basic characteristics of the patients with silicosis are listed in Table 1.

\begin{tabular}{|c|c|}
\hline \multicolumn{2}{|l|}{ Characteristics } \\
\hline Age (years & $64,08+/-6,46[46-81]$ \\
\hline Average duration of exposure (years) & $19,04+/-7,45[2-36]$ \\
\hline Delay between onset of exposure and onset of symptoms (years) & $18,07+/-9,5$ ans \\
\hline PPI & 42,45 \\
\hline$<40$ & 11,51 \\
\hline $40-70$ & 46,04 \\
\hline \multicolumn{2}{|l|}{$\geq 70$} \\
\hline Smoking status $(\%)$ & 53,9 \\
\hline Non-smoker & 34 \\
\hline Former smoker & 12,1 \\
\hline \multicolumn{2}{|l|}{ Smoker } \\
\hline \multicolumn{2}{|l|}{ Co-morbidities (\%) } \\
\hline - Tuberculosis & 8,33 \\
\hline - Heart disease & 11,9 \\
\hline - COPD & 31,97 \\
\hline \multicolumn{2}{|l|}{ Dyspnea $(\%)$} \\
\hline - Stage 1 & 17,01 \\
\hline - $\quad$ Stage 2 & 64,63 \\
\hline - $\quad$ Stage 3 & 17,01 \\
\hline - $\quad$ Stage 4 & 1,35 \\
\hline 6MWT average $(\mathrm{m})$ & $326,8+/-168,47$ \\
\hline \multicolumn{2}{|l|}{ SGRQ (\%) } \\
\hline - Total & $68,02+/-19,54$ \\
\hline - Symptoms & $45,95+/-23,66$ \\
\hline - Activities & $79,58+/-19,8$ \\
\hline - Impact & $68,32+/-22,33$ \\
\hline \multicolumn{2}{|l|}{ Test HAD } \\
\hline - Anxiety (\%) & 61,91 \\
\hline - $\quad$ Depression $(\%)$ & 83,67 \\
\hline
\end{tabular}

COPD: Chronic Obstructive Pulmonary Disease; PPI: Permanent Partial Impotence, 6-MWT: 6-Minute Walk Test, SGRQ: Saint-George Respiratory Questionnaire. 


\begin{tabular}{|c|c|c|c|c|}
\hline \multicolumn{4}{|c|}{ 6MWT } & \multirow[b]{2}{*}{$\mathrm{P}$} \\
\hline & $>300$ & $300-150$ & $<150$ & \\
\hline \multicolumn{5}{|c|}{ Duration of Exposure (\%) } \\
\hline - $\leq 10$ years & $9(45 \%)$ & $5(25 \%)$ & $6(30 \%)$ & \\
\hline - $10-20$ years & $41(74.54 \%)$ & $7(12.73 \%)$ & $7(12.73 \%)$ & \\
\hline - >20 years & $39(66.10 \%)$ & $8(13.58 \%)$ & $12(20.34 \%)$ & 0.17 \\
\hline \multicolumn{5}{|l|}{ Dyspnée N(\%) } \\
\hline - Stage 1 & $24(96 \%)$ & $1(4 \%)$ & $0(0 \%)$ & \\
\hline - Stage 2 & $65(70.65 \%)$ & $16(17.39 \%)$ & $11(11.96 \%)$ & \\
\hline - Stage 3 & $4(17.39 \%)$ & $4(17.39 \%)$ & $15(65.22 \%)$ & $<0,0001$ \\
\hline - Stage 4 & $0(0 \%)$ & $0(0 \%)$ & $1(100 \%)$ & \\
\hline \multicolumn{5}{|l|}{ SGRQ } \\
\hline -Total & $63,56+/-19,5^{*}$ & $69,79+/-21.01 *$ & $83.08+/-43,18 *$ & $\mathrm{P}=0,00001$ \\
\hline -Symptoms & $39,66+/-21,1 *$ & $52.06+/-25,62 *$ & $64,7+/-17,75^{*}$ & \\
\hline -Activites & $75,44+/-21,31 *$ & $82.49+/-16,47^{*}$ & $91.73+/-7,87 *$ & $\mathrm{P}<0,00001$ \\
\hline -Impact & $64,28+/-22,33$ & $68,13+/-25,07 *$ & $83,68+/-10,44^{*}$ & $\mathrm{P}=0,0004$ \\
\hline \multirow{2}{*}{\multicolumn{5}{|c|}{ HAD N(\%) }} \\
\hline & & & & \\
\hline $\begin{array}{l}\text { - Anxiety } \\
\text { Yes }\end{array}$ & $51(5731 \%)$ & $18(2022 \%)$ & $20(2247 \%)$ & - Anxiety \\
\hline No & $42(80.76 \%)$ & $3(5.76 \%)$ & $7(13 ? 48 \%)$ & $\mathrm{P}=0,0034$ \\
\hline \multicolumn{5}{|l|}{ - Depression } \\
\hline Yes & $74(62.71 \%)$ & $20(16.95 \%)$ & $24(20.34 \%)$ & \\
\hline No & $19(82.6 \%)$ & $1(4.34 \%)$ & $3(13.06 \%)$ & $\mathrm{P}=0,23$ \\
\hline
\end{tabular}

6-MWT: 6-Minute Walk Test, HAD: Hospital Anxiety and Depression

There is a statistically significant relationship between the duration of exposure and the degree of depression: higher the time of exposure, the higher the number of patients with depression $(\mathrm{p}=0.01)$

Anxious patients all have high QoL scores compared to silicosis patients without anxiety, and patients with depression had higher activity scores $(\mathrm{p}=0.00004)$ and total scores $(\mathrm{p}=$ 0.012) than non-depressed patients.

Table 3 shows the results of the univariate linear regression analysis with QoL scores as the baseline variables. Variables with a p $>0.05$ are not displayed in the table.

Age is associated with high activity score and Saint George total score, and time to onset of symptoms from the onset of anthrax exposure is related to the increased full quality of life score.

There is a correlation between PPI, walking distance WD, and saint george QOL scores. Therefore, as the ppi increases, the saint george questionnaire scores increase, indicating poor quality of life. Conversely, as walking distance increases, the scores are lower, reflecting better quality of life (except for WALKING DISTANCE, it is not correlated with SGT).

\begin{tabular}{|c|c|c|c|c|}
\hline Variables & Symptômes & Activités & Impact & Total \\
\hline Age & - & $0,04(0,646)$ & - & $0,04(0,6)$ \\
\hline Duration of exposure & - & - & - & - \\
\hline PPI & $0,05(0,271)$ & $0,04(0,183)$ & $0,04(0,223)$ & $0,03(0,221)$ \\
\hline Symptom onset time & - & - & - & - \\
\hline WD & $0,18(-0,059)$ & $0,07(-0,03)$ & $0,07(-0,035)$ & - \\
\hline
\end{tabular}

Time to Symptom Onset; Time to Symptom Onset in Relation to the Onset of Exposure, PPI: Permanent Partial Disability, WD: Walking Distance. 


\section{DISCUSSION}

This is the first study at the national level. It was conducted at the Pneumology and Silicosis Center of Jerada. Its purpose is to determine the clinical and functional profile and the healthrelated QoL of patients with silicosis.

The average age of our patients was $64.08+/-6.46$ years. It is close to that of the American patients in the Rosenman study [12], which was 69.5 years, higher than that of the Pérez study carried out in Spain, which was $52.6 \pm 10.7$ years. Aberkane.S [13] carried out the Algerian research where we have a relatively young population (33.75 years). However, it is lower than the Chinese patients, and the H Liu study published in 2011 and that of B. Han [8] published in 2013 (73.3 years and 74.1 years).

Only $8.3 \%$ of our patients had a history of tuberculosis, which is still very low compared to the study of H.Liu [14], where the percentage was $29.3 \%$, the one performed in Italy [15] $(43.75 \%)$ and the one of B. Han test [8] where it was $67 \%$.

In our study, the average duration of exposure to silica was 18.9 years [2 to 36 years]; for $\mathrm{H}$. Liu [14], it was 28.6, and for B.Han[8], [14] 27.9 years.

The inhalation of crystalline silica over prolonged periods leads to an impairment of lung function, which is manifested by a limitation in the 6-min walk test [8], [14], [16]

In our study, the mean distance walked was $329 \mathrm{~m}$, the median was $360 \mathrm{~m} .66 \%$ of our patients walked more than $300 \mathrm{~m}$ during the 6 -minute walk test. In the B. Han study, the median was $200 \mathrm{~m}$, and only $27 \%$ walked more than $250 \mathrm{~m}$. In the Pérez study [3], the mean distance walked was $387.9 \pm 91.7 \mathrm{~m}$, and $50 \%$ of patients walked less than $350 \mathrm{~m}$.

The Saint George questionnaire showed quite high scores reflecting a poor quality of life of our patients. This joins the results of Wang's study [17] where the mean of SGT, SGS, SGA, and SGI were 63.8+/-16.3; 62.3+/-15; 62.1+/-17.6; 66.9+/-22.6 respectively; and Liu H's study [14] where the mean of SGS, SGA, and SGI were 56.02, 56.46 and 52.33 respectively. Other studies [12], [17]-[19] using other QoL questionnaires (WHOQOL-100, SF36) showed that the QoL of silicosis was lower than that of control subjects.

B Han [20] also used the HAD test to evaluate the prevalence of anxiety and depression among silicosis patients $(\mathrm{N}=324)$ hospitalized in the department of pulmonology in Shenyang between April 2011 and September 2011. 99.1\% had symptoms of anxiety, and $86.1 \%$ had symptoms of depression. T.Yildiz [18] also reported that in Turkey, silicosis in sandblasters is accompanied by increased levels of anxiety and depressive symptoms (the author based his study on Beck's depression inventory (BDI scores) and Beck's anxiety inventory (BAI scores)). These results are similar to the results obtained in our patients, where the prevalence of anxiety was $61.91 \%$, and depression was $83.67 \%$.

A correlation between dyspnea, quality of life, anxiety, and walking distance was found in our study. Pérez [3] found that patients with a walking distance $<350 \mathrm{~m}$ are older and have more dyspnea $(\mathrm{p}<0.005)$. In the study of $\mathrm{B}$. Han [8], a significant association was found between the WALKING DISTANCE and the age of the patients $((>60$ years $) p<0.005)$, the duration of exposure ((duration $>15$ years) $p<0.05)$, as well as their quality of life $(p<0.01)$. No correlation was found between walking distance and age or WALKING DISTANCE and exposure duration in our study.

This study found a correlation between age and activity score and total quality of life score and a relationship between time to onset of symptoms from the start of exposure and TMS. These findings are consistent with data from other studies [17], [19]. However, our data did not show a relationship between the duration of exposure and the QoL of our patients, contrary to Liu's study [14].

\section{CONCLUSION}

The present study has shown that the 6-minute walk test is abnormal in most of our patients and correlates with their quality of life. Therefore, it has a great interest in the follow-up of our silicosis patients as it can reflect their clinical status and QoL. This study will be followed by a respiratory rehabilitation program and an evaluation of the impact of this rehabilitation in this population. 
Acknowledgments

None

Authors' contributions

The participation of each author corresponds to the criteria of authorship and contributorship emphasized in the Recommendations for the Conduct, Reporting, Editing, and Publication of Scholarly work in Medical Journals of the International Committee of Medical Journal Editors. Indeed, all the authors have actively participated in the redaction, the revision of the manuscript, and provided approval for this final revised version.

Funding

No funding was received from any organization to conduct the present study.

Conflict of interest

The authors declare that there is no conflict of interest regarding the publication of this article.

Ethical approval

None

\section{REFERENCES}

[1] Leung CC, Yu IT, Chen W. Silicosis. Lancet. 2012 May 26; 379(9830):2008-18. Doi: 10.1016/s0140-6736(12)60235-9

[2] Brichet A, Tillie-Leblond I, Wallaert B, Tonnel AB. Silicose et pneumoconiose du mineur de charbon. EMC Pneumol. 2004 ; 12. Doi: 10.1016/S1155-195X(00)00027$\underline{X}$

[3] Blanco Pérez JJ, Arnalich Montiel V, Salgado-Barreira Á, Alvarez Moure MA, Caldera Díaz AC, Cerdeira Dominguez L, et al. [The 6-Minute Walk Test as a Tool for Determining Exercise Capacity and Prognosis in Patients with Silicosis]. Arch Bronconeumol (Engl Ed). 2019 Feb; 55(2):88-92. Doi: 10.1016/j.arbres.2018.07.004

[4] Kauppinen T, Toikkanen J, Pedersen D, Young R, Ahrens W, Boffetta P, et al. Occupational exposure to carcinogens in the European Union. Occup Environ Med. 2000 Jan; 57(1):10-8. Doi: 10.1136/oem.57.1.10

[5] Coal worker's pneumoconiosis and silicosis. [Online]. 2012. [Accessed $2021 \mathrm{Apr}$ 06]. Available from:

https://www.hse.gov.uk/statistics/causdis/pneumoconiosis/index.htm

[6] Haut-Commisariat au Plan. Recensement Général de la population et de l'Habitat 2014 : Province de Jerada. 2016. [Online]. [Accessed 2021 Apr 06]. Available From: http://www.hcp.ma/regionoriental/docs/RGPH2014INDICATEURS/Indic2014 JE RADA.pdf.

[7] Hassi Blal. Un parc muséologique pour la mémoire industrielle et minière du royaume. [Online]. [Accessed 2021 Apr 06]. Available From: http://www.oriental.ma/upload/MoDUle 1/File 1 432.pdf.

[8] Han B, Yan B, Zhao N, Zhang J, Sun J, Lei X, et al. The influence of the functional capacity on subjective well-being and quality of life of patients with silicosis. Aging Ment Health. 2013;17(6):707-13. Doi: 10.1080/13607863.2013.788996

[9] Bouchet C, Guillemin F, Hoang Thi TH, Cornette A, Briançon S. Validation du questionnaire St Georges pour mesurer la qualité de vie chez les insuffisants respiratoires chroniques. Rev Mal Respir. 1996;13(1):43-6. [Accessed 2021 Sep 22]. Available From: https://splf.fr/wp-content/uploads/2014/11/StGeorges.pdf

[10] Préfaut C, Ninot G. La réhabilitation du malade respiratoire chronique. Elsevier Masson, 2009 Nov; 29(9):1018. Doi: 10.1016/S0761-8425(09)73342-X

[11] Ochmann U, Kotschy-Lang N, Raab W, Kellberger J, Nowak D, Jörres RA. Longterm efficacy of pulmonary rehabilitation in patients with occupational respiratory diseases. Respiration. 2012; 84(5):396-405. Doi: 10.1159/000337271

[12] Rosenman KD, Reilly MJ, Gardiner J. Results of spirometry among individuals in a silicosis registry. J Occup Environ Med. 2010 Dec; 52(12):1173-8. Doi: 10.1097/jom.0b013e3181fc5e50

[13] Aberkane S. Perceived Health Related Quality of Life Outcomes with Silicosis Patients. Iran J Public Health. 2017 Sep; 46(9):1299-1300. [Accessed 2021 Sep 22]. Available from: https://ijph.tums.ac.ir/index.php/ijph/article/view/11009

[14] Liu H, Yan B, Han B, Sun J, Yang Y, Chen J. Assessment of respiration- related quality of life of Chinese patients with silicosis and its influencing factors using the 
St. George's Respiratory Questionnaire (SGRQ),' J Clin Nurs. 2012 Jun;21(1112):1515-23. Doi: 10.1111/j.1365-2702.2011.03904.X

[15] Galietti F, Giorgis GE, Oliaro A, Ardizzi A, Miravalle C, Barberis S, et al. [Lung diseases associated with silicosis]. Study of 618 cases. Minerva Med. 1989 Sep; 80(9):987-90.

[16] Wang C, Yang LS, Shi XH, Yang YF, Liu K, Liu RY. Depressive symptoms in aged Chinese patients with silicosis. Aging Ment Health. 2008 May; 12(3):343-8. Doi: $\underline{10.1080 / 13607860802120938}$

[17] Li H, Lin M, Zhang W, Li J, Zou J. [Relationship between quality of life and disability level in patients with occupational disease]. Zhonghua Lao Dong Wei Sheng Zhi Ye Bing Za Zhi. 2015 Oct; 33(10):735-8.

[18] Yildiz T, Eşsizoğlu A, Onal S, Ateş G, Akyildiz L, Yaşan A, et al. Quality of life, depression and anxiety in young male patients with silicosis due to denim sandblasting. Tuberk Toraks. 2011; 59(2):120-5. Doi: $10.5578 /$ tt.1606

[19] Cheng C. [Quality of life and influencing factors for patients with silicosis: an analysis of 220 cases]. Zhonghua Lao Dong Wei Sheng Zhi Ye Bing Za Zhi. 2015 Feb; 33(2):116-8.

[20] Han B, Yan B, Zhang J, Zhao N, Sun J, Li C, et al. The influence of the social support on symptoms of anxiety and depression among patients with silicosis. ScientificWorldJournal. 2014; 2014:724804. Doi: 10.1155/2014/724804 